\title{
Postoperative complications after elective coronary artery bypass grafting surgery in patients with sleep-disordered breathing
}

\author{
Maria Tafelmeier ${ }^{1}$ (D) $\cdot$ Teresa Weizenegger $^{1} \cdot$ Sarah Ripfel $^{1} \cdot$ Miriam Fauser $^{1} \cdot$ Bernhard Floerchinger $^{2} \cdot$ \\ Daniele Camboni ${ }^{2} \cdot$ York Zausig $^{3} \cdot$ Sigrid Wittmann $^{3} \cdot$ Marzena A. Drzymalski $^{1} \cdot$ Florian Zeman $^{4} \cdot$ Christof Schmid $^{2}$. \\ Lars S. Maier ${ }^{1} \cdot$ Stefan Wagner ${ }^{1} \cdot$ Michael Arzt $^{1}$
}

Received: 9 January 2018 / Accepted: 5 June 2018 / Published online: 12 June 2018

c) Springer-Verlag GmbH Germany, part of Springer Nature 2018

\begin{abstract}
Background Sleep-disordered breathing (SDB) may increase the risk of postoperative complications in patients after cardiac surgery. This study evaluated the length of hospital stay as well as postoperative cardiac, respiratory, and renal complications after elective coronary artery bypass grafting (CABG) in patients without SDB, with central sleep apnea (CSA), or with obstructive sleep apnea (OSA).

Methods The presence and type of SDB had been assessed with polygraphic recordings in 100 patients the night before elective CABG surgery. SDB was defined as an apnea-hypopnea index (AHI) of $\geq 15 / h$. Prolonged length of hospital stay (LOS) and postoperative hemodynamic instability due to any cause were retrospectively evaluated as primary endpoints and cardiac, respiratory, and renal complications as secondary endpoints.

Results $37 \%$ of patients had SDB, 14\% CSA, and 23\% OSA. LOS differed significantly between patients without SDB and those with CSA and OSA [median (25;75. percentile): 8.0 days $(7.5 ; 11.0)$ vs. 9.5 days $(7.0 ; 12.5)$ vs. 12.0 days $(9.0 ; 17.0)$, Kruskal-Wallis test between three groups: $p=0.023$; OSA vs. no SDB: $p=0.005$ ]. AHI was significantly associated with prolonged LOS [ $>9$ days; odds ratio (OR) (95\% confidence interval): $1.047(1.001 ; 1.095), p=0.044$ ]. Prolonged need of vasopressors ( $\geq 48 \mathrm{~h}$ ) was observed in $36 \%$ of patients without SDB, in $64 \%$ with CSA, and in $62 \%$ with OSA $(p=0.037)$. AHI was significantly associated with prolonged ( $\geq 48 \mathrm{~h}$ ) need of vasopressors [OR (95\% CI): $1.052(1.002 ; 1.104), p=0.040]$, independent of any confounders.

Conclusions SDB, particularly OSA, is associated with prolonged LOS after CABG, independent of known confounders. Prolonged LOS in patients with SDB may be due to increased postoperative hemodynamic instability due to any cause.
\end{abstract}

Keywords Cardiac surgery $\cdot$ Coronary artery bypass grafting $\cdot$ Coronary artery disease $\cdot$ Sleep apnea

Maria Tafelmeier and Teresa Weizenegger contributed equally to this paper.

Electronic supplementary material The online version of this article (https://doi.org/10.1007/s00392-018-1289-0) contains supplementary material, which is available to authorized users.

Maria Tafelmeier

maria.tafelmeier@ukr.de

1 Department of Internal Medicine II (Cardiology, Pneumology, and Intensive Care), University Medical Centre Regensburg, Franz-Josef-Strauss-Allee 11, 93053 Regensburg, Germany

\section{Introduction}

Sleep-disordered breathing (SDB) is a common disorder with a range of harmful sequelae that affects approximately $13 \%$ of men and $6 \%$ of women aged between 30 and 70 years [1]. SDB has been linked to a number of severe health conditions, such as hypertension, type 2 diabetes mellitus, coronary artery disease, heart failure, and atrial

2 Department of Cardiothoracic Surgery, University Medical Centre Regensburg, Regensburg, Germany

3 Department of Anaesthesiology, University Medical Centre Regensburg, Regensburg, Germany

4 Centre for Clinical Studies, University Medical Centre Regensburg, Regensburg, Germany 
fibrillation [2-6]. About 25-40\% of patients with chronic heart failure are reported to have central sleep apnea (CSA) and 49-72\% obstructive sleep apnea (OSA) [4, 7].

Coronary artery bypass grafting (CABG) is the most frequently conducted cardiac surgery worldwide, and approximately 50,000 patients undergo CABG in Germany every year [8]. Despite major advances in surgery, patients undergoing CABG are still at substantial risk of developing cardiac, respiratory, and cerebrovascular complications [8].

SDB may increase the risk of peri- and postoperative complications [9]. Patients with SDB are more prone to develop cardiac complications such as myocardial infarction, arrhythmia, and cardiac arrest [4]. Observational studies in patients undergoing non-cardiac surgery suggest that SDB is associated with a higher rate of respiratory complications such as pneumonia or acute respiratory distress syndrome (ARDS) as well as with prolonged intubation and mechanical ventilation [9-12].

Data on patients developing perioperative complications after cardiac surgery are sparse [12-17]. Uchôa et al. found a higher rate of re-infarction and need of revascularization in the long-term outcome of patients with SDB and a higher incidence of atrial fibrillation in patients with SDB [16]. With respect to respiratory complications, patients with SDB are more likely to require prolonged intubation, mechanical ventilation, and tracheostomy due to postoperative hypoxemia $[13,14]$. Despite the association of SDB with postoperative complications, the impact of SDB on the total length of hospital stay (LOS) in patients undergoing non-cardiac or cardiac surgery is still unclear $[10,12]$.

Previous studies in patients undergoing cardiac surgery were limited by relatively small study populations and the fact that the type and severity of SDB were not taken into account [13-17]. Because most studies did not include a multivariable regression analysis $[12,13]$, the influence of potential confounders remains unclear.

Therefore, the aim of the present study was to evaluate cardiac, respiratory, and renal postoperative complications after elective CABG in patients without SDB, with CSA, and with OSA. The results of this study may contribute to optimizing the preoperative risk assessment as well as the peri- and postoperative management of patients with SDB undergoing elective cardiac surgery.

\section{Methods}

\section{Study population and study design}

Between October 2014 and March 2015, the presence of SDB had been assessed in 103 patients the night before they underwent elective CABG at the Department of Cardiothoracic Surgery of the University Medical Centre Regensburg (Germany). Three patients with a history of SDB were excluded. Thus, 100 patients were included in the analysis and classified according to the presence and type of SDB (Fig. 1). As a standard dose for premedication on the day
Fig. 1 Study flow chart. $S D B$ sleep-disordered breathing, $C A B G$ coronary artery bypass grafting, $A H I$ apnea-hypopnea index, CSA central sleep apnea, OSA obstructive sleep apnea

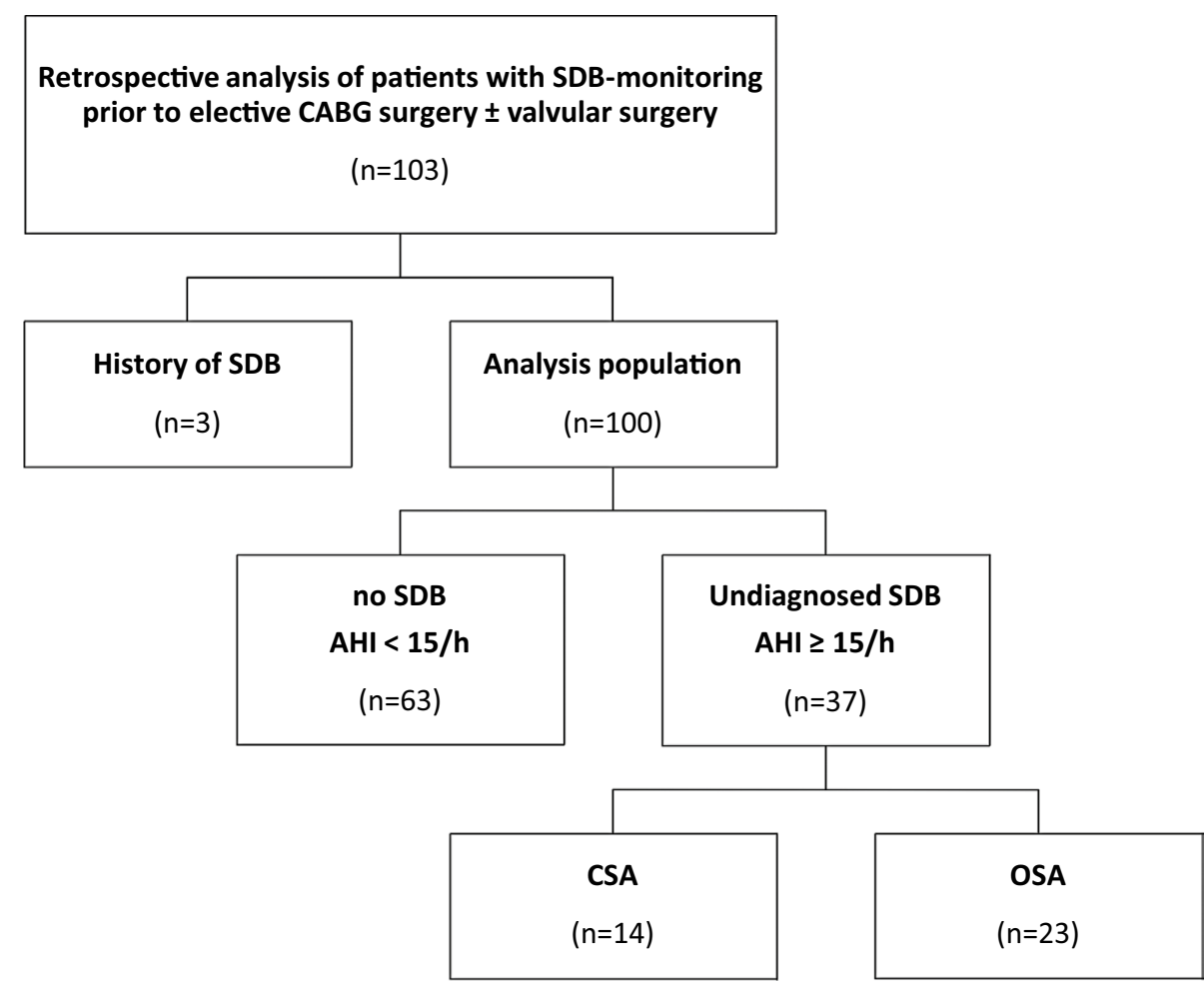


of surgery, patients were offered oral midazolam $7.5 \mathrm{mg}$, reduced to $3.75 \mathrm{mg}$ if they were aged $\geq 70$ years or if their body weight was $<50 \mathrm{~kg}$. Cardiac, respiratory, and renal postoperative complications as well as variables that may influence the perioperative risk, such as demographics, common comorbidities, cardiac catheterization results, and medication use, were retrospectively assessed by means of the patients' clinical records. Perioperative data were collected from the patients' surgical and anesthetic protocols. All pre- and postoperatively conducted diagnostic tests including echocardiograms, ECG recordings, chest X-rays, and laboratory data were taken into account. This retrospective analysis was approved by the Ethics Committee of the University of Göttingen (No. 14/09/11).

\section{Assessment of sleep-disordered breathing}

The night before CABG, nasal flow, pulse oximetry, and thoracic breathing effort had been measured with the ApneaLink device (ResMed Inc., Martinsried, Germany) that has been validated in several studies on patients with normal cardiac function $[4,18]$ and on patients with heart failure [7, 19].

As described previously [7], the default settings of the SDB monitoring device were used for defining apnea, hypopnea, and desaturation: apnea was defined as a $\geq 80 \%$ decrease in airflow for $\geq 10 \mathrm{~s}$ and hypopnea as a decrease in airflow by $\geq 50-80 \%$ versus baseline for $\geq 10$ s plus a $\geq 4 \%$ decrease in oxygen saturation. The apnea-hypopnea index (AHI) is expressed as the frequency of apnea or hypopneas per hour of sleep, and an AHI of $\geq 15 / \mathrm{h}$ was considered the cutoff for the diagnosis of SDB $[7,19]$. Patients with SDB and $>50 \%$ of central apneas were classified into the CSA group and patients with $\leq 50 \%$ of central apneas into the OSA group.

\section{Assessment of postoperative outcomes}

Prolonged LOS and postoperative hemodynamic instability due to any cause constituted the primary endpoint. The LOS-classified as the time between surgery and the day of discharge [14] — was considered prolonged when it was above the median length of hospitalization of all patients ( $>9$ days). We also compared the lengths of stay in the intensive care unit and the intermediate care unit with regard to SDB presence and type. Hemodynamic instability due to any cause was defined as the need of vasopressor or inotropes for $\geq 48 \mathrm{~h}$ after CABG [20].

In addition, significant cardiac, respiratory, and renal complications that might have contributed to the primary outcome served as secondary endpoints. Cardiac complications included new pulmonary oedema or increased use of diuretics as surrogate for worsening heart failure [21], and myocardial infarction indicated by troponin I values of $>10$ times the upper limit of normal or of $>5$ times the upper limit of normal in the presence of Q waves $(>0.04 \mathrm{~ms}$, $>1 \mathrm{mV})$, or by new ST-segment elevations $(>0.1 \mathrm{mV})$ [22]. Major adverse cardiac events (MACE) were myocardial infarction or revascularization [23].

Respiratory complications were respiratory failure or major pulmonary complications. Postoperative respiratory failure was defined as the need of prolonged mechanical ventilation of $>24 \mathrm{~h}$ or need of reintubation or tracheostomy [21]. ARDS, pneumonia, or pulmonary embolism represented major pulmonary complications.

Renal complications included postoperative acute kidney injury according to the KDIGO (Kidney Disease: Improving global outcomes) criteria defined as increase in serum creatinine of $\geq 0.3 \mathrm{mg} / \mathrm{dl}$ or of $\geq 1.5$ times baseline and need of renal replacement therapy [24].

\section{Statistical analysis}

Data are presented as mean \pm standard deviation unless otherwise indicated. Differences between characteristics and postoperative complications of patients without SDB or with CSA or OSA were compared using the analysis of variance (ANOVA) for normal distributed continuous variables, the Kruskal-Wallis test for non-normal distributed continuous variables, and the Chi-square test for categorical variables. Univariable logistic regression analyses were carried out with potential predictors of prolonged LOS ( $\leq 9$ vs. $>9 \mathrm{~h}$ ) and prolonged need of vasopressors ( $\leq 48 \mathrm{~h}$ vs. $>48 \mathrm{~h}$ ). Clinically important factors were additionally entered into multivariable logistic regression models. Two multivariable models for each dependent variable were used: model I accounted for demographic parameters [age, sex, and body mass index (BMI)], whereas model II was additionally adjusted for parameters reflecting comorbidities, cardiac damage, and perioperative risk [ASA-score, $\mathrm{N}$-terminal probrain natriuretic peptide (NT-proBNP), and bypass time]. A two-sided $p$ value of $<0.05$ was considered statistically significant for all analyses. No adjustments for multiple testing were made due to the exploratory character of this study. SPSS 23.0 software (IBM SPSS Statistics, Armonk, New York, USA) was used for statistical analyses.

\section{Results}

\section{Patient characteristics}

The baseline characteristics of all patients classified according to the presence and type of SDB are presented in Table 1. Patients with OSA were significantly older and had a significantly higher body mass index (BMI) than 
Table 1 Patient characteristics

\begin{tabular}{|c|c|c|c|c|}
\hline & No SDB & CSA & OSA & $p$ value \\
\hline \multicolumn{5}{|l|}{ General data } \\
\hline$n(\%)$ & $63(63)$ & $14(14)$ & $23(23)$ & \\
\hline Age, years ${ }^{\mathrm{a}}$ & $66 \pm 10$ & $69 \pm 9$ & $72 \pm 7^{f}$ & $0.046^{b}$ \\
\hline Male sex, $n(\%)$ & $49(78)$ & $14(100)$ & $21(91)$ & $0.067^{\mathrm{c}}$ \\
\hline Body mass index, $\mathrm{kg} / \mathrm{m}^{2 \mathrm{a}}$ & $28.0 \pm 4.0$ & $29.4 \pm 4.0$ & $30.3 \pm 4.6^{\mathrm{f}}$ & $0.066^{\mathrm{b}}$ \\
\hline Midazolam, $n(\%)$ & $48(77)$ & $10(71)$ & $14(61)$ & $0.312^{\mathrm{c}}$ \\
\hline \multicolumn{5}{|l|}{ Nocturnal respiration } \\
\hline AHI, per hour & $6(4 ; 9)$ & $27(21 ; 39)^{\mathrm{e}}$ & $21(18 ; 26)^{\mathrm{f}}$ & $<\mathbf{0 . 0 0 1}^{\mathrm{d}}$ \\
\hline Apnea index, per hour & $2(1 ; 4)$ & $12(9 ; 29)^{\mathrm{e}}$ & $8(4 ; 15)^{\mathrm{f}}$ & $<\mathbf{0 . 0 0 1}^{\mathrm{d}}$ \\
\hline Obstructive apnea index, per hour & $1(0 ; 2)$ & $3(1 ; 6)^{e}$ & $8(4 ; 12)^{f}$ & $<\mathbf{0 . 0 0 1}^{\mathrm{d}}$ \\
\hline Central apnea index, per hour & $0(0 ; 2)$ & $9(7 ; 27)^{\mathrm{e}, \mathrm{g}}$ & $2(0 ; 3)^{\mathrm{f}, \mathrm{g}}$ & $<\mathbf{0 . 0 0 1}^{\mathrm{d}}$ \\
\hline Min. $\mathrm{SpO}_{2}, \%$ & $81(78 ; 83)$ & $78(74 ; 81)$ & $79(73 ; 81)^{\mathrm{f}}$ & $\mathbf{0 . 0 1 1}^{\mathrm{d}}$ \\
\hline Median $\mathrm{SpO}_{2}, \%$ & $93(92 ; 94)$ & $93(92 ; 94)$ & $92(90 ; 94)$ & $0.052^{\mathrm{d}}$ \\
\hline \multicolumn{5}{|l|}{ Comorbidities } \\
\hline ASA class III/IV, $n(\%)$ & $57(91)$ & $14(100)$ & $21(100)$ & $0.169^{c}$ \\
\hline Hypertension, $n(\%)$ & $56(89)$ & $14(100)$ & $21(91)$ & $0.421^{\mathrm{c}}$ \\
\hline Hyperlipoproteinemia, $n(\%)$ & $37(59)$ & $10(71)$ & $13(57)$ & $0.787^{\mathrm{c}}$ \\
\hline Diabetes mellitus, $n(\%)$ & $15(24)$ & $3(21)^{\mathrm{g}}$ & $13(57)^{\mathrm{f}, \mathrm{g}}$ & $0.012^{c}$ \\
\hline Smokers, $n(\%)$ & $41(70)$ & $9(69)$ & $13(59)$ & $0.664^{\mathrm{c}}$ \\
\hline Heart failure, $n(\%)$ & $30(48)$ & $10(71)$ & $19(86)^{\mathrm{f}}$ & $0.004^{c}$ \\
\hline NT-proBNP, pg/ml & $439(140 ; 987)$ & $585(112 ; 1119)^{\mathrm{g}}$ & $1525(734 ; 4059)^{\mathrm{f}, \mathrm{g}}$ & $\mathbf{0 . 0 0 3}^{\mathrm{d}}$ \\
\hline LV ejection fraction, $\%^{\mathrm{a}}$ & $55 \pm 12$ & $40 \pm 6$ & $42 \pm 17^{\mathrm{f}}$ & $\mathbf{0 . 0 0 5}^{\mathrm{a}}$ \\
\hline Previous myocardial infarction, $n(\%)$ & $21(34)$ & $8(57)$ & $6(27)$ & $0.167^{\mathrm{c}}$ \\
\hline Previous PTCA, $n(\%)$ & $18(29)$ & $6(46)$ & $4(17)$ & $0.184^{\mathrm{c}}$ \\
\hline Atrial fibrillation, $n(\%)$ & $9(14)$ & $4(29)$ & $7(30)$ & $0.174^{\mathrm{c}}$ \\
\hline Creatinine, $\mathrm{mg} / \mathrm{dl}$ & $1.0(0.9 ; 1.1)$ & $1.0(0.9 ; 1.1)$ & $1.1(1.0 ; 1.6)^{\mathrm{f}}$ & $0.040^{\mathrm{d}}$ \\
\hline $\mathrm{GFR}, \mathrm{ml} / \mathrm{min} / 1.73 \mathrm{qm}$ & $75(60 ; 87)$ & $61(67 ; 97)$ & $63(34 ; 83)^{\mathrm{f}}$ & $0.071^{\mathrm{d}}$ \\
\hline \multicolumn{5}{|l|}{ Perioperative data } \\
\hline CABG and valve replacement, $n(\%)$ & $10(16)$ & $2(14)$ & $6(26)$ & $0.511^{\mathrm{c}}$ \\
\hline Bypass time, $\min$ & $88(65 ; 120)$ & $80(68 ; 112)$ & $105(76 ; 117)$ & $0.363^{\mathrm{d}}$ \\
\hline Number of performed grafts & $2.6 \pm 1.0$ & $2.6 \pm 0.8$ & $2.5 \pm 1.1$ & $0.948^{\mathrm{d}}$ \\
\hline
\end{tabular}

Baseline variables of the study patients without SDB, with CSA, and with OSA. Data are presented as mean \pm standard deviation or median (25.; 75. percentile), unless stated otherwise

NYHA New York Heart Association, NT-pro BNP N-terminal pro-brain natriuretic peptide, $L V$ left ventricular, PTCA percutaneous transluminal coronary angioplasty, ASA American Society of Anesthesiologists

${ }^{\mathrm{a}} \mathrm{Mean} \pm \mathrm{SD}$

${ }^{b}$ ANOVA

${ }^{\mathrm{c}}$ Chi square

${ }^{\mathrm{d}}$ Kruskal-Wallis test

${ }^{\mathrm{e}} \mathrm{p}_{\text {CSA vs. no SDB }}<0.05$

${ }^{\mathrm{f}} \mathrm{p}_{\text {OSA vs. no SDB }}<0.05$

${ }^{\mathrm{g}} \mathrm{p}_{\text {CSA vs. OSA }}<0.05$

patients without SDB. Patients with OSA were significantly more often diagnosed with heart failure and had a significantly lower left ventricular ejection fraction and significantly higher NT-pro BNP values than patients without SDB and patients with CSA. Moreover, patients with OSA were significantly more likely to have diabetes mellitus than patients without SDB and patients with CSA.
Patients with OSA were also significantly more prone to suffer from impaired renal function indicated by significantly higher creatinine levels and significantly lower GFR levels than patients without SDB. The three patient groups did neither significantly differ with regard to hypertension, hyperlipoproteinemia, their smoking status, previous 
myocardial infarction, or PTCA nor with respect to the type of surgical procedure and perioperative data.

\section{Sleep-disordered breathing}

$37 \%$ of the 100 patients were diagnosed with SDB (AHI of $\geq 15 / \mathrm{h}$ ). CSA was present in $14 \%$ and OSA in $23 \%$ of all patients. By definition, the AHI was significantly higher in patients with CSA or OSA than in patients without SDB. In comparison to patients without $\mathrm{SDB}$, minimum oxygen saturation levels were significantly lower in the CSA group and the OSA group (Table 1). Administration of midazolam did not significantly differ among patients without SDB, with CSA, or with OSA (Table 1). There was no statistically significant difference in AHI and median oxygen saturation between patients who received midazolam compared to those who did not take midazolam on the day of CABG surgery [AHI $9(4.25 ; 19)$ vs. $12(5 ; 24)$, Kruskal-Wallis test $p=0.271$; median oxygen saturation: $93(91 ; 94)$ vs. 92 (91;93), Kruskal-Wallis test $p=0.253]$.

\section{Assessment of postoperative outcomes}

\section{Prolonged length of hospital stay}

The median length of hospital stay was 9 days for all patients and varied significantly between subgroups [no SDB 8.0 days $(7.5 ; 11.0)$ vs. CSA 9.5 days $(7.0 ; 12.5)$ vs. OSA 12.0 days $(9.0 ; 17.0)$; Kruskal-Wallis test between three groups: $p=0.023$; OSA vs. no SDB: $p=0.005$; Fig. 2a]. Prolonged LOS defined by a median split ( $\leq 9$ vs. $>9$ days) was
Fig. 2 Length of hospital stay and need of vasopressors. The boxplot depicts the length of hospital stay and the length of stay on ICU and IMC for patients with CSA, with OSA, or without SDB (a). The box represents the interquartile range (IQR), and the line inside the box the median. The upper whisker is drawn from the upper edge of the box to the largest value within $1.5 \times \mathrm{IQR}$; the lower whisker from the lower edge of the box to the smallest value within $1.5 \times$ IQR. Circles, squares, and triangles indicate values outside $1.5 \times \mathrm{IQR}$. Percentages of patients requiring vasopressors for $\geq 48 \mathrm{~h}$ are shown for the group without SDB, with CSA, and with OSA (Chi-square test, b). SDB sleep-disordered breathing, $C S A$ central sleep apnea, $O S A$ obstructive sleep apnea, $I C U$ intensive care unit, IMC intermediate care unit
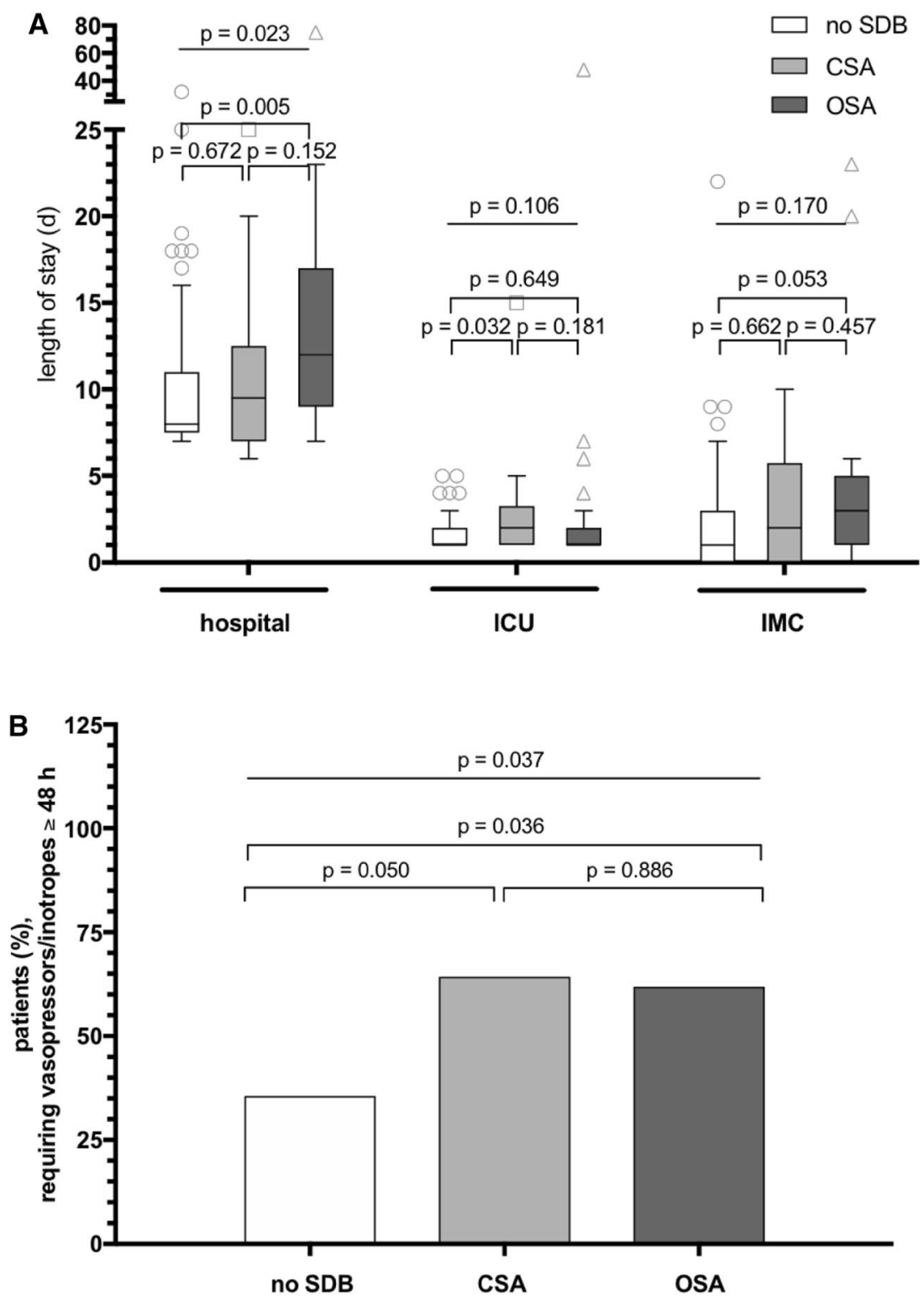
significantly more common in patients with OSA $(p=0.035$, Table 2) than in patients without SDB.

In univariable logistic regression analyses, prolonged LOS after CABG was significantly associated with AHI, diagnosis of OSA, the oxygen desaturation index (ODI), time of $\mathrm{SaO}_{2}<90 \%, \mathrm{BMI} \geq 30 \mathrm{~kg} / \mathrm{m}^{2}$, and a left ventricular ejection fraction of $<50 \%$ (Table 3 ). The association between AHI and prolonged LOS remained significant in both multivariable logistic regression models [model I: OR (95\% confidence interval, CI) 1.046 (1.004; 1.089), $p=0.031$; model II: OR (95\% CI) 1.047 (1.001; 1.095), $p=0.044 ;$ e-Table 1$]$.

Important pre- and postoperative determinants for prolonging LOS are presented in Fig. 3. The presence of OSA was associated with a significant increase in median LOS by 3.5 days (Fig. 3a). Other significant preoperative determinants for a prolonged LOS were BMI $\geq 30 \mathrm{~kg} / \mathrm{m}^{2}, \mathrm{SDB}$, $\geq 65$ years of age, and diastolic dysfunction (Fig. 3a). Significant postoperative determinants for a prolonged LOS were respiratory failure, ventilation of $>24 \mathrm{~h}$, need of dialysis, fever, major pulmonary complications, acute myocardial infarction, and a C-reactive protein level of $\geq 100 \mathrm{mg} / \mathrm{dl}$ (Fig. 3b).

\section{Postoperative hemodynamic instability due to any cause}

Compared to $36 \%$ of patients without SDB, $64 \%$ of patients with CSA and $62 \%$ of patients with OSA needed vasopressors or inotropes for $\geq 48 \mathrm{~h}$ (Fig. 2b). Thus, patients with CSA or OSA were significantly more likely to develop hemodynamic instability due to any cause than those without SDB. In univariable regression analyses (Table 3), prolonged need for vasopressors or inotropes was significantly associated with AHI, OSA, ODI, and bypass time. However, cardiovascular risk factors (i.e., age, male sex, body mass index, or hypertension), preoperative NT-pro BNP, or type of surgery (i.e., number of distal anastomoses and $\mathrm{CABG} \pm$ valve replacement) were not significantly associated with prolonged need for vasopressors or inotropes. Using the multivariable regression models described in
Table 2 Postoperative complications

\begin{tabular}{|c|c|c|c|c|}
\hline & No SDB & CSA & OSA & $p$ value \\
\hline Prolonged length of hospital stay (>9 days), $n(\%)$ & $19(31)$ & $7(50)$ & $14(61)^{\mathrm{d}}$ & $\mathbf{0 . 0 3 5}$ \\
\hline \multicolumn{5}{|l|}{ Postoperative cardiac parameters } \\
\hline Need of vasopressors for $\geq 24 \mathrm{~h}, n(\%)$ & $35(58)$ & $13(93)^{\mathrm{c}}$ & $14(67)$ & $\mathbf{0 . 0 5 0} 0^{\mathrm{a}}$ \\
\hline MACE, $n(\%)$ & $18(29)$ & $5(36)$ & $10(44)$ & $0.446^{\mathrm{a}}$ \\
\hline Myocardial infarction, $n(\%)$ & $15(25)$ & $5(36)$ & $8(35)$ & $0.563^{\mathrm{a}}$ \\
\hline Need of revascularisation, $n(\%)$ & $2(9)$ & $1(7)$ & $7(11)$ & $0.881^{\mathrm{a}}$ \\
\hline Furosemide equivalent dose $\mathrm{e}_{\text {postoperative, }} \mathrm{mg}$ & $50(30 ; 93)$ & $60(30 ; 115)^{\mathrm{e}}$ & $125(38 ; 255)^{\mathrm{e}, \mathrm{f}}$ & $0.001^{b}$ \\
\hline Postoperative increase of loop diuretics, $\mathrm{mg}$ & $40(20 ; 80)$ & $50(28 ; 115)$ & $75(38 ; 255)$ & $0.235^{\mathrm{b}}$ \\
\hline Pulmonary edema, $n(\%)$ & $53(84)$ & $13(93)$ & $20(91)$ & $0.557^{\mathrm{b}}$ \\
\hline \multicolumn{5}{|l|}{ Postoperative respiratory parameters } \\
\hline Respiratory failure, $n(\%)$ & $3(5)$ & $2(14)$ & $3(14)$ & $0.299^{\mathrm{a}}$ \\
\hline Reintubation, $n(\%)$ & $0(0)$ & $0(0)$ & $1(5)$ & $0.171^{\mathrm{a}}$ \\
\hline Tracheostomy, $n(\%)$ & $0(0)$ & $0(0)$ & $2(9)^{d}$ & $\mathbf{0 . 0 2 8}^{\mathrm{a}}$ \\
\hline Major pulmonary complications, $n(\%)$ & $11(18)$ & $2(14)$ & $6(27)$ & $0.531^{\mathrm{a}}$ \\
\hline Pneumonia, $n(\%)$ & $10(16)$ & $2(14)$ & $5(23)$ & $0.728^{\mathrm{a}}$ \\
\hline ARDS, $n(\%)$ & $0(0)$ & $1(7)$ & $1(5)$ & $0.145^{\mathrm{a}}$ \\
\hline \multicolumn{5}{|l|}{ Postoperative renal parameters } \\
\hline Acute kidney injury, $n(\%)$ & $22(35)$ & $5(36)$ & $12(55)$ & $0.256^{\mathrm{a}}$ \\
\hline Max. creatinine, mg/dl & $1.2(1.0 ; 1.6)$ & $1.0(0.9 ; 1.4)^{\mathrm{e}}$ & $1.6(1.1 ; 2.6)^{\mathrm{d}, \mathrm{e}}$ & $0.015^{b}$ \\
\hline Min. GFR, $\mathrm{ml} / \mathrm{min} / 1.73 \mathrm{qm}$ & $60(41 ; 75)$ & $68(45 ; 89)^{\mathrm{e}}$ & $41(23 ; 69)^{\mathrm{d}, \mathrm{e}}$ & $\mathbf{0 . 0 2 9} 9^{b}$ \\
\hline Dialysis, $n(\%)$ & $3(5)$ & $0(0)$ & $3(13)$ & $0.219^{\mathrm{a}}$ \\
\hline
\end{tabular}

Complication rates for prolonged length of stay and postoperative cardiac, respiratory, and renal parameters of patients without SDB, with CSA, and with OSA

$M A C E$ major adverse cardiac events, ARDS acute respiratory distress syndrome

${ }^{\mathrm{a}} \mathrm{Chi}$ square

${ }^{\mathrm{b}}$ Kruskal-Wallis test

${ }^{\mathrm{c}} \mathrm{p}_{\text {CSA vs. no SDB }}<0.05$;

${ }^{\mathrm{d}} \mathrm{p}_{\text {OSA vs. no SDB }}<0.05$

${ }^{\mathrm{e}} \mathrm{p}_{\text {CSA vs. OSA }}<0.05$ 
Table 3 Predictors for prolonged length of hospital stay and prolonged need of vasopressors

\begin{tabular}{|c|c|c|c|c|}
\hline \multirow{2}{*}{$\begin{array}{l}\text { Univariable analysis } \\
\text { Variable }\end{array}$} & \multicolumn{2}{|c|}{ Prolonged LOS ( $>9$ days) } & \multicolumn{2}{|c|}{$\begin{array}{l}\text { Prolonged need of vasopressors } \\
(>48 \mathrm{~h})\end{array}$} \\
\hline & OR $(95 \% \mathrm{CI})$ & $p$ value & OR $(95 \% \mathrm{CI})$ & $p$ value \\
\hline \multicolumn{5}{|l|}{ SDB } \\
\hline AHI & $1.05(1.01 ; 1.10)$ & 0.007 & $1.06(1.02 ; 1.11)$ & 0.006 \\
\hline OSA (reference: no SDB) & $3.34(1.24 ; 9.01)$ & 0.017 & $2.94(1.05 ; 8.23)$ & 0.040 \\
\hline CSA (reference: no SDB) & $2.15(0.66 ; 6.96)$ & 0.201 & $3.26(0.97 ; 10.99)$ & 0.057 \\
\hline ODI & $1.05(1.01 ; 1.10)$ & 0.011 & $1.06(1.01 ; 1.10)$ & 0.010 \\
\hline $\mathrm{SaO}_{2}<90 \%$ & $1.00(1.00 ; 1.01)$ & 0.020 & $1.00(1.00 ; 1.00)$ & 0.897 \\
\hline Age, years & $1.03(0.99 ; 1.09)$ & 0.147 & $1.04(1.00 ; 1.09)$ & 0.080 \\
\hline Male sex & $2.36(0.70 ; 7.93)$ & 0.164 & $2.68(0.79 ; 9.14)$ & 0.115 \\
\hline $\mathrm{BMI} \geq 30, \mathrm{~kg} / \mathrm{m}^{2}$ & $3.78(1.55 ; 9.24)$ & 0.003 & $1.17(0.49 ; 2.81)$ & 0.719 \\
\hline $\begin{array}{l}\text { ASA class III/IV (reference: ASA } \\
\text { class I/II) }\end{array}$ & $1.35(0.23 ; 7.73)$ & 0.739 & $0.83(0.16 ; 4.36)$ & 0.829 \\
\hline Hypertension & $0.38(0.08 ; 1.94)$ & 0.245 & $2.11(0.47 ; 9.37)$ & 0.329 \\
\hline NT-pro BNP, pg/ml & $1.17(0.96 ; 1.43)$ & 0.121 & $1.28(0.99 ; 1.67)$ & 0.063 \\
\hline LV ejection fraction $<50 \%$ & $3.18(1.12 ; 9.05)$ & $\mathbf{0 . 0 3 0}$ & $2.03(0.70 ; 5.86)$ & 0.190 \\
\hline CABG and valve replacement & $2.06(0.73 ; 5.77)$ & 0.171 & $1.42(0.50 ; 4.08)$ & 0.512 \\
\hline Distal anastomosis & $0.99(0.65 ; 1.51)$ & 0.954 & $1.12(0.73 ; 1.73)$ & 0.613 \\
\hline Bypass time, min & $1.01(1.00 ; 1.02)$ & 0.063 & $1.01(1.00 ; 1.02)$ & 0.037 \\
\hline
\end{tabular}

Univariable regression analysis. Association of SDB and baseline parameters with prolonged length of hospital stay and prolonged need of vasopressors

Values are presented as $O R$ odds ratio and $95 \% C I$ confidence interval. LOS length of hospital stay, ODI oxygen desaturation index, $\mathrm{SaO}_{2}$ oxygen saturation of arterial blood, $L V$ left ventricular

\begin{abstract}
"Methods" section, alongside age only AHI was found to be significantly associated with the prolonged need for vasopressors or inotropes independent from any potential confounders [model I: OR (95\% CI) 1.051 (1.007; 1.097), $p=0.021$; model II: OR (95\% CI) 1.052 (1.002; 1.104), $p=0.040]$. Please refer to e-Table 2 for more details.
\end{abstract}

\section{Heart failure and MACE}

Development of pulmonary oedema was similar between the three patient groups. The equivalent furosemide dose was significantly higher in patients with OSA than in patients without SDB or with CSA (Table 2). Regarding the occurrence of MACE and myocardial infarction, no statistical difference was found among patients with CSA, with OSA or without SDB (Table 2).

\section{Respiratory failure}

Although duration of mechanical ventilation was numerically twofold higher among patients with OSA than in patients without SDB, there was no significant difference between patient groups (e-Fig. 2). Postoperative ventilation for $\geq 24 \mathrm{~h}$ was associated with AHI (OR 1.064, $p=0.011$ ) and the obstructive apnea index (OR 1.114, $p=0.050$ ). Patients with OSA required tracheostomy significantly more often than patients without SDB or with CSA (Table 2). The incidence of major pulmonary complications, pneumonia, and ARDS was similar among patients with CSA, with OSA, or without SDB.

\section{Renal complications}

OSA was associated with impaired renal function as indicated by significantly higher creatinine values and significantly lower glomerular filtration rates than those of patients without SDB or with CSA (Table 2). The three patient groups did not significantly differ with regard to acute kidney injury and need for renal replacement therapy.

\section{Discussion}

The study provides novel insights into the impact of SDB on LOS and postoperative complications. First, undiagnosed SDB with an AHI of $\geq 15 / \mathrm{h}$ was detected in $37 \%$ of all patients undergoing elective $\mathrm{CABG}$, and $14 \%$ of patients had CSA and 23\% OSA. Second, patients with OSA required a significantly prolonged hospital stay by 4 days compared to patients without SDB. The severity of SDB assessed by the AHI was associated with prolonged LOS, independent of any known risk factors that may prolong LOS. Third, patients with SDB were at greater risk of developing postoperative hemodynamic instability due to any cause and 
Fig. 3 Determinants of length of stay. Comparison of the length of hospital stay (LOS) with or without the presence of the respective preoperative (a) and postoperative (b) parameter. NYHA New York Heart Association, $B M I$ body mass index, $A S A$ American Society of Anesthesiologists, $L V E F$ left ventricular ejection fraction, $C R P$ C-reactive protein. See

Fig. 1 legend for expansion of abbreviations. Data are given as medians. ${ }^{*} p$ value $<0.05$
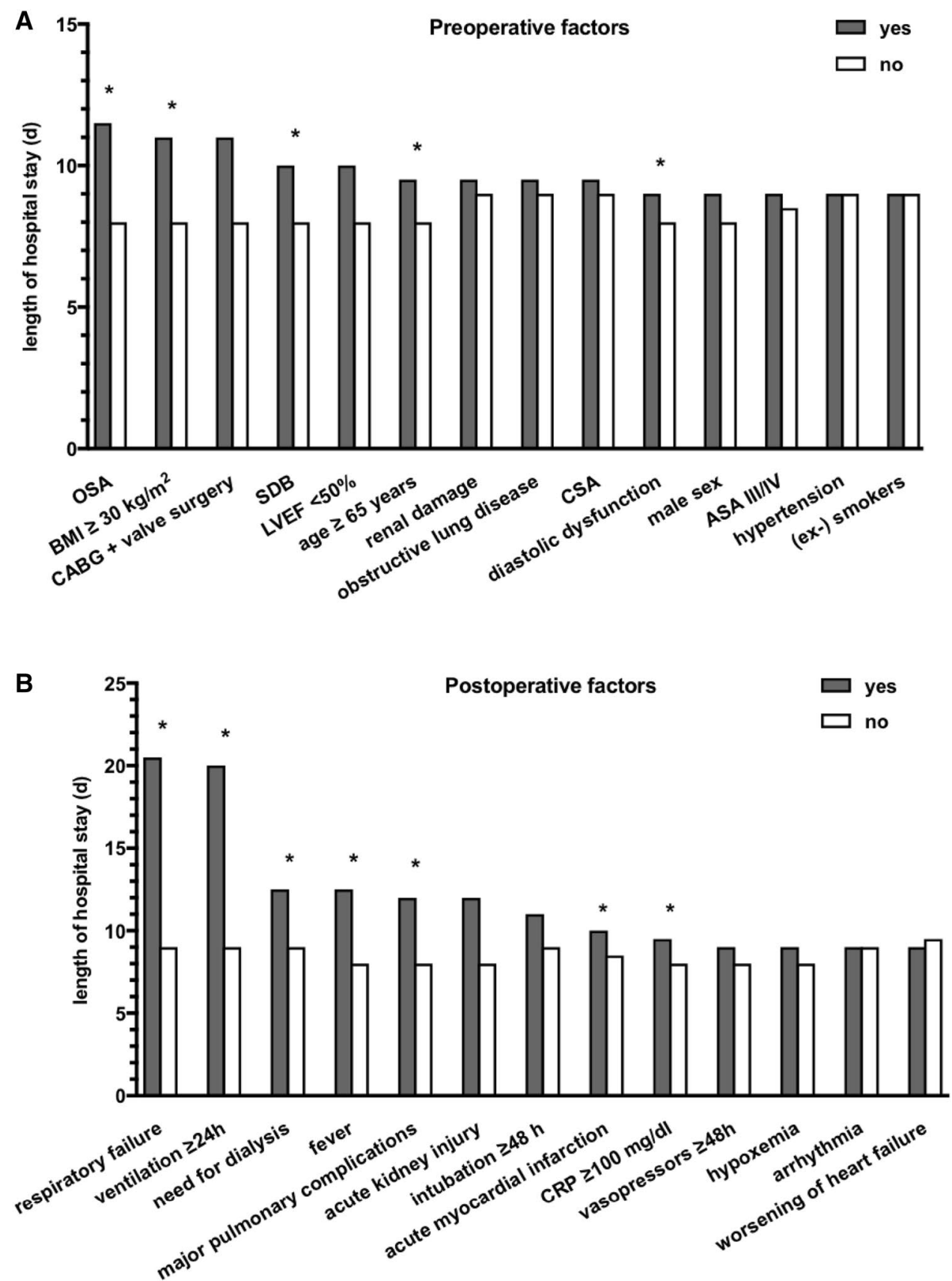

heart failure as indicated by a significantly prolonged need of vasopressors ( $\geq 48 \mathrm{~h}$ ) and increased postoperative use of diuretics.

\section{Prevalence of undiagnosed SDB}

In our study, undiagnosed SDB with an AHI of $\geq 15 / \mathrm{h}$ was found in $37 \%$ of all patients undergoing elective CABG; OSA accounted for the majority of cases of SDB. Because many patients undergoing $\mathrm{CABG}$ suffer from heart failure and components of the metabolic syndrome linked to SDB, the prevalence of undiagnosed SDB is remarkably high among patients referred for CABG $[7,25]$. Our findings are in accordance with previous studies analyzing SDB in coronary artery disease that found SDB in $29-64 \%$ of all patients [17]. Discrepancies in prevalence rates between these studies may derive from varying definitions and diagnosis of SDB and its subtypes, using either the Berlin questionnaire (41\%) [13], polygraphy with a portable monitor (59 vs. $29 \%$ : before vs. 2 weeks after surgery) [17, 26], or PSG (56\%) [16].

Patients receiving premedication with benzodiazepine agonists, such as zolpidem and eszopiclone, had similar AHI and oxygen saturation nadir [27] compared to those without sedative premedication. The effects of a premedication 
by midazolam in an OSA patient population were reported by Gentil et al., who demonstrated that midazolam did not increase the number of apneas or the incidence of oxygen desaturation in OSA patients [28]. Besides, there is evidence from multiple studies $[29,30]$ that midazolam in similar doses has no significant effects on AHI and median oxygen saturation. Correspondingly, premedication with midazolam was not associated with significant changes in AHI or median oxygen saturation in our patient population.

To our knowledge, this is the first study addressing the association between SDB and postoperative complications that differentiates between patients without SDB and patients with CSA or OSA. So far, all studies available on this subject have merely compared two groups of patients: patients with OSA and SDB and patients without OSA and SDB (see e-Table 3). Approximately, one-third of patients undergoing $\mathrm{CABG}$ suffer from heart failure with a reduced ejection fraction [31]. Although CSA may be less prevalent in the general population than OSA, prevalence estimates for CSA among patients with chronic heart failure vary between 30 and 50\% [32]. Thus, a significant proportion of patients undergoing CABG may be assumed to have CSA. Previous studies on patients undergoing CABG that included a significant proportion of patients with heart failure did not consider CSA (see e-Table 3); yet, we found CSA to be present in 14\% of our study cohort. To truly understand the impact of SDB and its subtypes on the postoperative outcome of cardiac patients, CSA must not be ignored in the analysis.

\section{Impact of SDB on LOS}

In the present study, patients with OSA had a significantly prolonged LOS. An AHI of $\geq 15 / \mathrm{h}$ was independently associated with LOS, prolonging hospitalization by 4 days in patients with OSA compared to patients without SDB. This finding is consistent with a previous study by Bhama et al. [14], in which the diagnosis of OSA significantly increased LOS after CABG from 13 to 24 days. However, diagnosis of OSA in their study was mainly based on the presence of clinical criteria (snoring, persistent daytime sleepiness or drowsiness while driving, obesity, or hypertension) instead of polygraphic recordings; thus, no distinction was made between OSA and CSA.

Though it was tempting to speculate that the prolongation of LOS in our study could be attributed to higher comorbidity rates among patients with SDB, we did not find any relevant influence of demographic parameters or comorbidities on the independent association between an AHI of $\geq 15 / \mathrm{h}$ and prolonged LOS. Therefore, prolongation may have been caused by the summation of postoperative complications of patients with OSA.

Our findings indicate that the presence or absence of certain pre- and postoperative risk factors can be used to predict which patients will require prolonged LOS after CABG. Remarkably, diagnosis of OSA was found to be an important preoperative risk factor, emphasizing the impact of SDB on LOS. Consistent with our results, Lazar et al. identified respiratory insufficiency, intubation, and inotropic support for $\geq 48 \mathrm{~h}$, arrhythmia, and myocardial infarction to be predictive of prolonged LOS after CABG [33]. Other important determinants of prolonged LOS were wound infection [33], congestive heart failure, and chronic renal disease [34].

New postoperative care protocols, such as "fast-track recovery" that aims for early extubation and mobilization, contribute to a significant reduction in postoperative ICU- and hospital length of stay after cardiac surgery [35]. All of our study patients received postoperative treatment accordingly. Moreover, less invasive methods for myocardial revascularization, such as off-pump cardiac surgery and minimally invasive direct coronary artery bypass grafting (MID$\mathrm{CAB}$ ), were developed over the last two decades to reduce surgical trauma and length of hospital stay [36, 37]. However, as data on the benefits and risks of these approaches compared to cardiopulmonary bypass are inconclusive [38-41], we apply these methods only to a small number of selected patients and all of our study patients underwent onpump CABG. Recently, hybrid coronary revascularization that combines both surgical and percutaneous revascularization strategies was shown to reduce postoperative duration of hospitalization [42] and may be a promising approach for future patients.

With in-hospital treatment costs in the United States of approximately $\$ 20,000-\$ 25,000$ [26, 43], CABG ties up substantial financial resources. According to Eisenberg et al., the daily costs of a bed in an ICU in the United States are $\$ 1121.81$ and $\$ 561.53$ on a surgical ward [43]. Because of increasing health care costs, patients at risk of prolonged LOS should be identified at an early stage. Moreover, each additional day in hospital increases the risk of adverse drug reactions by $0.5 \%$, of infection by $1.6 \%$, and of ulcers by $0.5 \%$ [44]. Thus, prolonged LOS may be a potential risk factor for adverse events during in-patient care.

\section{Impact of SDB on hemodynamic instability and cardiovascular complications}

The present study extends previous findings by showing that SDB in patients undergoing CABG is associated with postoperative hemodynamic instability due to any cause and heart failure as indicated by increased use of vasopressors or inotropes and diuretics, independent of the severity of heart failure prior to $\mathrm{CABG}$ surgery. Findings have to be interpreted in the light of evidence that there is a bi-directional relationship between SDB and hemodynamic instability or heart failure. Fluid overload in heart failure with consecutive nocturnal rostral fluid shift was found to be associated 
with upper airway narrowing [45] and instability of ventilatory control [46]. Consequently, rostral fluid shift contributes to the severity of both OSA and CSA $[46,47]$ and is directly linked to the degree of leg oedema and sitting time, and inversely linked to the degree of physical activity [46]. This mechanism may be alleviated by an improvement of cardiac function and subsequently by less leg oedema and rostral fluid shift. Conversely, sleep apnea may contribute to worsening of heart failure by exposing the heart to intermittent hypoxia, increased preload and afterload, sympathetic activation and vascular endothelial dysfunction [48]. Previous studies have shown that OSA increases the risk of postoperative atrial fibrillation in patients after CABG $[16,17]$, possibly due to mechanisms deriving from shared risk factors, autonomic instability, and atrial remodeling $[49,50]$. Numerous studies have affirmed the association between SDB and higher rates of postoperative arrhythmia (e-Table 3) [11, 13, 17, 51], but MACE has so far only been investigated in one study by Uchôa et al. [16]. In the longterm follow-up, MACE and repeated revascularization procedures were significantly more common in patients with SDB than in patients without OSA [16]. However, none of the existing studies evaluating SDB as a risk factor for perioperative complications has had a sufficient sample size to analyze MACE in a meaningful manner $[9,12-14,16]$. Nevertheless, the higher rates of MACE and revascularization procedures found among our patients with SDB corresponded to the results by Uchôa et al. [16] and might be significant in the long-term outcome, a factor that was not investigated in our study. Present findings justify the further investigation of the association between SDB and MACE in future large-scale prospective studies (CONSIDER-AF, ClinicalTrials.gov Identifier: NCT02877745).

\section{Pathophysiology}

Although several theories on pathophysiology have been identified, the mechanistic link between SDB and an unfavorable postoperative outcome is not yet fully understood. As reviewed by Vasu et al., sedatives, anesthetics, and opioids administered during the peri- and postoperative period may increase upper airway collapsibility, reduce hypoxic and hypercapnic ventilator response, and increase the threshold for arousal from sleep, which ultimately intensifies SDB and may thus increase the risk of postoperative complications [52]. In patients with heart failure, obstructive sleep events reduce cardiac output, resulting in substantial adverse hemodynamic effects [53]. However, hemodynamic compromise due to obstructive sleep apnea may be amenable to CPAP therapy [54]. Vasoactive agents used to improve hemodynamic stability postoperatively increase oxygen demand and may subsequently raise the risk of ischemia [55]. In a previous study, use of inotropes and vasopressors was associated with increased morbidity, including a higher rate of postoperative myocardial infarction, stroke, arrhythmia, and need of renal replacement therapy [55]. Therefore, use of vasoactive agents should be limited to their short-term hemodynamic benefits in patients after cardiac surgery.

\section{Limitations}

Limitations of the present analysis are the retrospective study design and the small sample size. Due to the small sample size multivariable regression models should be interpreted with caution. Because of the lack of data derived from standardized blood samples, regular oxygen measurements, or long-term ECG-monitoring, certain postoperative complications, such as deteriorating blood values and episodes of hypoxemia or arrhythmia (e.g., atrial fibrillation), may have remained undetected.

This study was conducted by means of a portable polygraphic system, whereas PSG is still considered the gold standard for diagnosing SDB. Differentiating between CSA and OSA with polygraphy may be more imprecise compared to PSG, since sleep stages are not assessed [56].

\section{Conclusion and clinical implication}

This study suggests that SDB, particularly OSA, is associated with prolonged LOS after CABG, independent of known confounders. Prolonged LOS in patients with SDB may be due to increased postoperative hemodynamic instability due to any cause.

Although SDB is a common disorder among cardiac surgery patients, the majority of patients affected by SDB remain undiagnosed [57]. The high rate of undiagnosed SDB in patients undergoing $\mathrm{CABG}$ and its impact on postoperative complications and LOS demand effective preventive and therapeutic strategies. Our findings support the recommendations to incorporate systematic identification of patients with SDB into the routine preoperative risk assessment of cardiac surgery patients [56, 58]. According to current guidelines on SDB and perioperative management [58], all patients should be preoperatively assessed for their risk of SDB. A preoperative evaluation should include a comprehensive review of previous medical records regarding, e.g., a history of airway difficulty, hypertension and other cardiovascular problems, an interview with the patient focusing on questions related to snoring, apnoeic episodes, frequent arousals during sleep, morning headaches and daytime somnolence, as well as a physical examination with respect to airway and nasopharyngeal characteristics, neck circumference, tonsil size and tongue volume [58]. Elective patients with a high pre-test probability of SDB should undergo 
thorough SDB-screening before surgery. Within the postoperative care of patients with SDB, special emphasis should be put on the appropriate use of sedatives and opioids, the continuous administration of oxygen or CPAP therapy, nonsupine positioning, and adequate monitoring [58].

The data of the present analysis emphasize the need for further larger scale prospective studies (NCT02877745) that are needed to identify specific risks and risk populations in cardiac surgery. Based on this knowledge, peri- and postoperative management of patients with SDB may be optimized to further minimize the rate of postoperative complications.

\section{Compliance with ethical standards}

Conflict of interest MA has received research grants and lecture fees from Philips Respironics and ResMed. The remaining authors declare no conflict of interest

\section{References}

1. Peppard PE, Young T, Barnet JH, Palta M, Hagen EW, Hla KM (2013) Increased prevalence of sleep-disordered breathing in adults. Am J Epidemiol 177(9):1006-1014

2. Aronsohn RS, Whitmore H, van Cauter E, Tasali E (2010) Impact of untreated obstructive sleep apnea on glucose control in type 2 diabetes. Am J Respir Crit Care Med 181(5):507-513

3. Gami AS, Pressman G, Caples SM et al (2004) Association of atrial fibrillation and obstructive sleep apnea. Circulation 110(4):364-367

4. Javaheri S, Parker TJ, Liming JD (1998) Sleep apnea in 81 ambulatory male patients with stable heart failure. Types and their prevalences, consequences, and presentations. Circulation 97(21):2154-2159

5. Peker $\mathrm{Y}$, Kraiczi H, Hedner J, Loèth $\mathrm{S}$, Johansson A, Bende M (1999) An independent association between obstructive sleep apnoea and coronary artery disease. Eur Respir J 14(1):179-184

6. Peppard PE, Young T, Palta M, Skatrud J (2013) Prospective study of the association between sleep-disordered breathing and hypertension. Am J Epidemiol 177(9):1006-1014

7. Arzt M, Oldenburg O, Graml A et al (2016) Prevalence and predictors of sleep-disordered breathing in patients with stable chronic heart failure: the SchlaHF registry. JACC Heart Fail $4: 116-125$

8. Beckmann A, Funkat AK, Lewandowski J (2015) Cardiac surgery in Germany during 2014: a report on behalf of the German Society for Thoracic and Cardiovascular Surgery. Thorac Cardiovasc Surg Rep 63(4):258-269

9. Memtsoudis S, Liu SS, Ma Y et al (2011) Perioperative pulmonary outcomes in patients with sleep apnea after noncardiac surgery. Anesth Analg 112(1):113-121

10. Gupta RM, Parvizi J, Hanssen AD, Gay PC (2001) Postoperative complications in patients with obstructive sleep apnea syndrome undergoing hip or knee replacement: a case-control study. Mayo Clin Proc 76(9):897-905

11. Kaw R, Chung F, Pasupuleti V, Mehta J, Gay PC, Hernandez AV (2012) Meta-analysis of the association between obstructive sleep apnoea and postoperative outcome. Br J Anaesth 109(6):897-906

12. Kaw R, Golish J, Ghamande S, Burgess R, Foldvary N, Walker E (2006) Incremental risk of obstructive sleep apnea on cardiac surgical outcomes. J Cardiovasc Surg 47(6):683-689
13. Amra B, Niknam N, Sadeghi M et al (2014) Obstructive sleep apnea and postoperative complications in patients undergoing coronary artery bypass graft surgery: a need for preventive strategies. Int J Prev Med 5(11):1446-1451

14. Bhama JK, Spagnolo S, Alexander EP, Greenberg M, Trachiotis GD (2006) Coronary revascularization in patients with obstructive sleep apnea syndrome. Heart Surg Forum 9(6):E813-817

15. Roggenbach J, Klamann M, von Haken R, Bruckner T, Karck M, Hofer S (2014) Sleep-disordered breathing is a risk factor for delirium after cardiac surgery: a prospective cohort study. Crit Care 18(5):477

16. Uchôa CHG, Danzi-Soares NdJ, Nunes FS (2015) Impact of OSA on cardiovascular events after coronary artery bypass surgery. Chest 147(5):1352-1360

17. Unosawa S, Sezai A, Akahoshi T et al (2012) Arrhythmia and sleep-disordered breathing in patients undergoing cardiac surgery. J Cardiol 60(1):61-65

18. Chen H, Lowe AA, Bai Y, Hamilton P, Fleetham JA, Almeida FR (2009) Evaluation of a portable recording device (ApneaLink) for case selection of obstructive sleep apnea. Sleep Breath 13:213-219

19. Weinreich G, Armitstead J, Töpfer V, Wang YM, Wang Y, Teschler H (2009) Validation of ApneaLink as screening device for Cheyne-Stokes respiration. Sleep 32(4):553-557

20. Mohammed AA, Agnihotri AK, van Kimmenade RRJ et al (2009) Prospective, comprehensive assessment of cardiac troponin $\mathrm{T}$ testing after coronary artery bypass graft surgery. Circulation 120(10):843-850

21. Kaw R, Pasupuleti V, Walker E, Ramaswamy A, FoldvarySchafer N (2012) Postoperative complications in patients with obstructive sleep apnea. Chest 141(2):436-441

22. Somers VK, Dyken ME, Clary MP, Abboud FM (1995) Sympathetic neural mechanisms in obstructive sleep apnea. J Clin Invest 96(4): 1897-1904

23. Biancari F, Ruggieri VG, Perrotti A et al (2015) European Multicenter Study on Coronary Artery Bypass Grafting (E-CABG registry). Study protocol for a prospective clinical registry and proposal of classification of postoperative complications. J Cardiothorac Surg 10(1):90

24. Mehta RL, Kellum JA, Shah SV et al (2007) Acute Kidney Injury Network: report of an initiative to improve outcomes in acute kidney injury. Crit Care 1(2):R31

25. Danzi-Soares NJ, Nerbass FB, Pedrosa RP et al (2012) Obstructive sleep apnea is common among patients referred for coronary artery bypass grafting and can be diagnosed by portable monitoring. Coron Artery Dis 23(1):31-38

26. Reynolds MR, Neil N, Ho KK, Berezin R, Cosgrove RS, Lager RA, Sirois C, Johnson RG, Cohen DJ (2003) Clinical and economic outcomes of multi vessel coronary stenting compared with bypass surgery: a single-center US experience. Am Heart J 145:334-342

27. Smith PR, Sheikh KL, Costan-Toth C, Forsthoefel D, Bridges E, Andrada TF, Holley AB (2017) Eszopiclone and zolpidem do not affect the prevalence of the low arousal threshold phenotype. J Clin Sleep Med 13(1):115-119

28. Gentil B, Tehindrazanarivelo A, Lienhart A, Meyer B, Fleury B (1994) Respiratory effects of midazolam in patients with obstructive sleep apnea syndromes. Ann Fr Anesth Reanim 13(3):275-279

29. Genta PR, Eckert DJ, Gregorio MG, Danzi NJ, Moriya HT, Malhotra A, Lorenzi-Filho G (2011) Critical closing pressure during midazolam-induced sleep. J Appl Physiol (1985) 111(5):1315-1322

30. Gregório MG, Jacomelli M, Inoue D, Genta PR, de Figueiredo AC, Lorenzi-Filho G (2011) Comparison of full versus short 
induced-sleep polysomnography for the diagnosis of sleep apnea. Laryngoscope 121(5):1098-1103

31. Topkara VK, Cheema FH, Kesavaramanujam S, Mercando ML, Cheema AF, Namerow PB, Argenziano M, Naka Y, Oz MC, Esrig BC (2005) Coronary artery bypass grafting in patients with low ejection fraction. Circulation 112(9 Suppl):I344-I350

32. Linz D, Fox H, Bitter T, Spießhöfer J, Schöbel C, Skobel E, Türoff A, Böhm M, Cowie MR, Arzt M, Oldenburg O (2016) Impact of SERVE-HF on management of sleep disordered breathing in heart failure: a call for further studies. Clin Res Cardiol 105(7):563-570

33. Lazar HL, Fitzgerald C, Gross S, Heeren T, Aldea GS, Shemin RJ (1995) Determinants of length of stay after coronary artery bypass graft surgery. Circulation 92(9):20-24

34. Ghali WA, Hall RE, Ash AS, Moskowitz MA (1999) Identifying pre- and postoperative predictors of cost and length of stay for coronary artery bypass surgery. Am J Med Qual 14(6):248-254

35. Walji S, Peterson RJ, Neis P, DuBroff R, Gray WA, Benge W (1999) Ultra-fast track hospital discharge using conventional cardiac surgical techniques. Ann Thorac Surg 67(2):363-369 (discussion 369-70)

36. Puskas JD, Thourani VH, Marshall JJ, Dempsey SJ, Steiner MA, Sammons BH, Brown WM III, Gott JP, Weintraub WS, Guyton RA (2001) Clinical outcomes, angiographic patency, and resource utilization in 200 consecutive off-pump coronary bypass patients. Ann Thorac Surg 71(5):1477-1483 (discussion 1483-4)

37. Martinovic I, Lindemann S, Irqsusi M, Mirat J, Vcev A, Wittlinger T, Noutsias M (2018) Minimally invasive direct coronary bypass surgery via distal mini-sternotomy: Promising clinical results with anaortic, multivessel, all-arterial technique. Herz. https:// doi.org/10.1007/s00059-018-4696-0 (Epub ahead of print)

38. Lamy A, Devereaux PJ, Prabhakaran D, Taggart DP, Hu S, Straka Z, Piegas LS, Avezum A, Akar AR, Lanas Zanetti F, Jain AR, Noiseux N, Padmanabhan C, Bahamondes JC, Novick RJ, Tao L, Olavegogeascoechea PA, Airan B, Sulling TA, Whitlock RP, Ou Y, Gao P, Pettit S, Yusuf S (2016) CORONARY Investigators. Five-year outcomes after off-pump or on-pump coronary-artery bypass grafting. N Engl J Med 375(24):2359-2368

39. Kowalewski M, Pawliszak W, Malvindi PG, Bokszanski MP, Perlinski D, Raffa GM, Kowalkowska ME, Zaborowska K, Navarese EP, Kolodziejczak M, Kowalewski J, Tarelli G, Taggart DP, Anisimowicz L (2016) Off-pump coronary artery bypass grafting improves short-term outcomes in high-risk patients compared with on-pump coronary artery bypass grafting: meta-analysis. J Thorac Cardiovasc Surg 151(1):60-77

40. Doenst T, Essa Y, Jacoub K, Moschovas A, Gonzalez-Lopez D, Kirov H, Diab M, Bargenda S, Faerber G (2017) Cardiac surgery 2016 reviewed. Clin Res Cardiol 106(11):851-867

41. Doenst T, Strüning C, Moschovas A, Gonzalez-Lopez D, Essa Y, Kirov H, Diab M, Faerber G (2016) Cardiac surgery 2015 reviewed. Clin Res Cardiol 105(10):801-814

42. Giambruno V, Hafiz A, Fox SA, Jeanmart H, Cook RC, Khaliel FH, Teefy P, Sridhar K, Lavi S, Bagur R, Randhawa VK, Iglesias I, Jones PM, Harle CC, Bainbridge D, Chu MW, Kiaii BB (2017) Is the future of coronary arterial revascularization a hybrid approach?: the Canadian experience across three centers. Innovations (Phila) 12(2):82-86

43. Eisenberg MJ, Filion KB, Azoulay A, Brox AC, Haider S, Pilote L (2005) Outcomes and cost of coronary artery bypass graft surgery in the United States and Canada. Arch Intern Med 165:1506-1513

44. Hauck K, Zhao X (2011) How dangerous is a day in hospital? A model of adverse events and length of stay for medical inpatients. Med Care 49(12):1068-1075
45. Chiu KL, Ryan CM, Shiota S, Ruttanaumpawan P, Arzt M, Haight JS, Chan CT, Floras JS, Bradley TD (2006) Fluid shift by lower body positive pressure increases pharyngeal resistance in healthy subjects. Am J Respir Crit Care Med 174(12):1378-1383

46. Yumino D, Redolfi S, Ruttanaumpawan P, Su MC, Smith S, Newton GE, Mak S, Bradley TD (2010) Nocturnal rostral fluid shift: a unifying concept for the pathogenesis of obstructive and central sleep apnea in men with heart failure. Circulation 121(14):1598-1605

47. Redolfi S, Yumino D, Ruttanaumpawan P, Yau B, Su MC, Lam J, Bradley TD (2009) Relationship between overnight rostral fluid shift and Obstructive Sleep Apnea in nonobese men. Am J Respir Crit Care Med 179(3):241-246

48. Buchner S, Greimel T, Hetzenecker A, Luchner A, Hamer OW, Debl K, Poschenrieder F, Fellner C, Riegger GA, Pfeifer M, Arzt M (2012) Natural course of sleep-disordered breathing after acute myocardial infarction. Eur Respir J 40(5):1173-1179

49. Digby GC, Baranchuk A (2012) Sleep apnea and atrial fibrillation; 2012 update. Curr Cardiol Rev 8(4):265-272

50. Strotmann J, Fox H, Bitter T, Sauzet O, Horstkotte D, Oldenburg O (2018) Characteristics of sleep-disordered breathing in patients with atrial fibrillation and preserved left ventricular ejection fraction. Clin Res Cardiol 107(2):120-129

51. Liao P, Yegneswaran B, Vairavanathan S, Zilberman P, Chung F (2009) Postoperative complications in patients with obstructive sleep apnea: a retrospective matched cohort study. Can J Anaesth 56(11):819-828

52. Vasu TS, Grewal R, Doghramji K (2012) Obstructive sleep apnea syndrome and perioperative complications: a systematic review of the literature. J Clin Sleep Med 8(2):199-207

53. Yumino D, Kasai T, Kimmerly D, Amirthalingam V, Floras JS, Bradley TD (2013) Differing effects of obstructive and central sleep apneas on stroke volume in patients with heart failure. Am J Respir Crit Care Med 187(4):433-438

54. Mansfield DR, Gollogly NC, Kaye DM, Richardson M, Bergin P, Naughton MT (2004) Controlled trial of continuous positive airway pressure in obstructive sleep apnea and heart failure. Am J Respir Crit Care Med 169(3):361-366

55. Nielsen DV, Hansen MK, Johnsen SP, Hansen M, Hindsholm K, Jakobsen CJ (2014) Health outcomes with and without use of inotropic therapy in cardiac surgery. Anesthesiology 120(5):1098-1108

56. Mayer G, Arzt M, Braumann B, Ficker JH, Fietze I, Frohnhofen H, Galetke W, Maurer JT, Orth M, Penzel T, Randerath W, Rösslein M, Sitter H, Stuck BA (2017) S3-Leitlinie Nicht erholsamer Schlaf/ Schlafstörungen - Kapitel "Schlafbezogene Atmungsstörungen bei Erwachsenen”. Somnologie 20(Suppl. s2):97-180

57. Hwang D, Shakir N, Limann B et al (2008) Association of sleepdisordered breathing with postoperative complications. Chest 133(5):1128-1134

58. Gross JB, Apfelbaum JL, Caplan RA, Connis RT, Coté CJ, Nickinovich DG, Ward DS, Weaver EM, Ydens L (2014) Practice guidelines for the perioperative management of patients with obstructive sleep apnea: an updated report by the American Society of Anesthesiologists Task Force on Perioperative Management of patients with obstructive sleep apnea. Anesthesiology 120(2):268-286 